\title{
CHEMICAL ORDERING OF Ag-Au ALLOYS IN THE MOLTEN STATE
}

\section{Ishwar Koirala}

Journal of Institute of Science and Technology

Volume 22, Issue 2, January 2018

ISSN: 2469-9062 (print), 2467-9240 (e)

\section{Editors:}

Prof. Dr. Kumar Sapkota

Prof. Dr. Armila Rajbhandari

Assoc. Prof. Dr. Gopi Chandra Kaphle

Mrs. Reshma Tuladhar

JIST, 22 (2): 191-201 (2018)

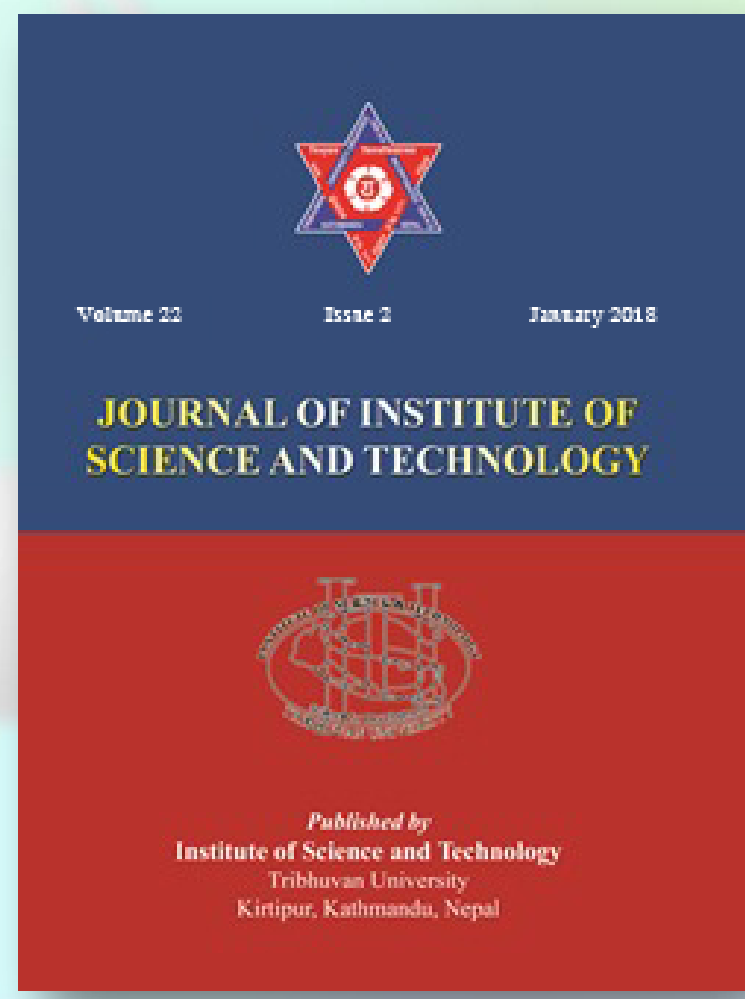

Published by:

Institute of Science and Technology

Tribhuvan University

Kirtipur, Kathmandu, Nepal 


\title{
CHEMICAL ORDERING OF Ag-Au ALLOYS IN THE MOLTEN STATE
}

\author{
Ishwar Koirala \\ Central Department of Physics, Tribhuvan University, Kirtipur, Nepal \\ Corresponding E-mail: ikphysicstu@gmail.com
}

Received: 28 September, 2017; Revised: 26 December, 2017; Accepted: 29 December, 2017

\begin{abstract}
Simple statistical model has been used to report the thermodynamic, structural, transport and surface properties of liquid Ag-Au alloys at 1350K. In thermodynamic properties we have studied the free energy of mixing, heat of mixing, entropy of mixing and the chemical activity of both components of the alloys. For the structural investigation, our study includes concentration fluctuation in long wave length limit and Warren-Cowley short range order parameter. Viscosity and diffusivity of the alloys have been studied to understand transport properties. The surface behavior has been analyzed by computing surface concentration and surface tension of the alloys. The structural behaviors of the alloys are found to be symmetric with respect to concentrations of the species. The computed results are in good agreement with experimental data. Positive deviation of viscosity isotherms from linear law is observed. Surface tension of the alloys is found to be smaller than ideal values throughout bulk concentration of silver. For all theoretical analysis, concentration independent energy parameter takes important role, which is found to be temperature dependent and finally analysis confirms that presented alloy is hetero-coordinated.
\end{abstract}

Keywords: Simple statistical model, Ideality, Hetero-coordinated alloys, Surface properties, Chemical Ordering.

\section{INTRODUCTION}

The alloying of silver with other elements is practiced in order to achieve increased hardness and wear-resistance of deposits and higher stability tarnishing antifriction properties (Jha et al., 2014). It has been used as electroplated deposit because of its increased hardness and wear-resistance, in turn leads to the use of smaller plate thickness and consequent saving of expensive materials. The significance of Ag-based alloys is also important in brazing and welding processes. The wetting phenomena between the filling alloys melt (brazing alloys) and the base materials have a central role in obtaining sufficient quality, which serve the formation of steady joints between the parts. Alloying elements are also often used for these purposes in order lower the melting point and for increasing the wettability between the parts to be fixed (Jha et al., 2014; Andrews, 1978).

Nowadays the solders contain little amount of gold, because a few percent gold can increase the quality of the joint. In the Mendeleev periodic table silver and gold are in the same column, so the E/A (electron/atom) ratio is the same. The atomic diameter of the silver and gold are almost the same $\sim 2.88 \mathrm{~A}$ and $2.92 \mathrm{~A}$ (www.keytometals). Both elements have the same fcc crystal structure and there is no big differences between electronegativities. Therefore material pair meets HumeRothery rules. The concentration dependent properties of $\mathrm{Ag}-\mathrm{Au}$ liquid alloys are interesting in many ways; especially it is used for preparation of jewelry. The knowledge of mixing properties of liquid alloys is necessary for design and development of reliable materials. For the material preparation of metal alloys, the understandings of mixing properties of liquid alloys are important. Several theoretical models (Anusionwu et al., 1998; Prasad et al., 1998; Akinlade et al., 2002; Novakovic, 2010; Kumar et al., 2013; Koirala et al., 2013; Singh et al., 2014) have long been proposed to understand the thermodynamic, structural, transport and surface properties of binary liquid alloys. The computational models for the calculation of band structure calculations for binary, ternary and quaternary alloys have also proposed by various 
authors (Pandey et al., 2014; Poudel \& Kaphle, 2016; Kaphle et al., 2012 \& 2015; Pandey \& Kaphle, 2017; Ghimire et al., 2016; Sharma and Kaphle, 2017; Sedhain and Kaphle, 2017).

In present work, we study the concentration dependent mixing properties of liquid $\mathrm{Ag}-\mathrm{Au}$ at $1350 \mathrm{~K}$ by the simple statistical model (Singh et al., 1990; Koirala et al., 2014). The energetic of mixing as well as the positive/negative deviation from Raoult's law for the various bulk and surface properties have been discussed.

The paper is arranged as follows: We present theoretical formalism in section 2, results and discussions in section 3 and finally, conclusion of the paper is presented in section 4 .

\section{THEORETICAL FORMALISM}

\section{Thermodynamic properties}

The grand partition function for simple binary liquid alloys $A B$ which consists of $\mathrm{N}_{\mathrm{A}}(=\mathrm{N}$ x $)$ number of $A$ atoms and $N_{B}(=N(1-x))$ number of $B$ atoms so that total number atoms $\mathrm{N}$, becomes equal to $\mathrm{N}_{\mathrm{A}}+\mathrm{N}_{\mathrm{B}}$, may be expressed as (Singh et al.,1990)

$$
\begin{aligned}
& \Xi=\left[\phi_{A} q_{A}(T)\right]^{N_{A}}\left[\phi_{B} q_{B}(T)\right]^{N_{B}} \exp (-\beta E), \\
& \beta=1 / k_{B} T
\end{aligned}
$$

where $\mathrm{q}_{i}^{\mathrm{N}_{\mathrm{i}}}$ are the partition functions of atoms ( $\mathrm{i}=\mathrm{A}$ or $\mathrm{B}$ ) associated with inner and translational degree of freedom. $q_{i}$ the same whether the atom $i$ is located in the pure state or in alloy. $\phi_{\mathrm{i}}(\mathrm{i}=\mathrm{A}$ or $\mathrm{B})$ stands for

$$
\phi_{\mathrm{i}}=\exp \left(\mu_{\mathrm{i}} / \mathrm{k}_{\mathrm{B}} \mathrm{T}\right)
$$

where $\mu_{\mathrm{i}}, \mathrm{k}_{\mathrm{B}}$ and $\mathrm{T}$ refer to chemical potential of ith component, Boltzmann constant and absolute temperature, respectively. $\mathrm{E}$ is the configurational energy of the alloys. One can easily obtain a relation between excess free energy of mixing, $\mathrm{G}_{\mathrm{M}}^{\mathrm{XS}}$ and the ratio of activity coefficients, $\gamma\left(=\gamma_{\mathrm{A}} /\right.$ $\gamma_{B}$ ) by solving equation (1) in the framework of simple statistical model (Koirala et al., 2014).

$$
\mathrm{G}_{\mathrm{M}}^{\mathrm{XS}}=\mathrm{RT} \int_{0}^{\mathrm{x}} \ln \gamma \mathrm{dx}=\mathrm{RT}\left[\mathrm{x} \ln \gamma_{\mathrm{A}}+(1-\mathrm{x}) \ln \gamma_{\mathrm{B}}\right]
$$

with $\gamma_{\mathrm{A}}=[(\beta-1+2 \mathrm{x}) / \mathrm{x}(1+\beta)]^{\mathrm{z} / 2}$

$$
\gamma_{\mathrm{B}}=[(\beta+1-2 \mathrm{x}) /(1-\mathrm{x})(1+\beta)]^{\mathrm{z} / 2}
$$$$
\beta=\left\{1+4 \mathrm{x}(1-\mathrm{x})\left[\exp \left(2 \omega / \mathrm{zk}_{\mathrm{B}} \mathrm{T}\right)-1\right]\right\}^{1 / 2}
$$

where, $\mathrm{R}$ is universal molar constant; $\mathrm{x}$, concentration of the component; $\omega$, interchange or ordering energy and $\mathrm{z}$, coordination number. For the equi-atomic composition $\left(\mathrm{x}=\frac{1}{2}\right)$, relation (3) reduces to

$$
\frac{\mathrm{G}_{\mathrm{M}}^{\mathrm{XS}}}{\mathrm{RT}}=\ln 2^{\mathrm{z} / 2}\left[1+\exp \left(-\omega / \mathrm{zk}_{\mathrm{B}} \mathrm{T}\right)\right]^{-\mathrm{z} / 2}
$$

The standard thermodynamic relation for excess free energy of mixing and free energy of mixing $\left(\mathrm{G}_{\mathrm{M}}\right)$ is

$$
\mathrm{G}_{\mathrm{M}}^{\mathrm{XS}}=\mathrm{G}_{\mathrm{M}}-\mathrm{RT}[\mathrm{x} \ln \mathrm{x}+(1-\mathrm{x}) \ln (1-\mathrm{x})]
$$

Using the relations (3) and (8), one obtains an expression for the free energy of mixing [Guggenheim, 1952] as

$$
\begin{aligned}
\mathrm{G}_{\mathrm{M}} & =\mathrm{RT}\left[\mathrm{x} \ln \mathrm{x}+(1-\mathrm{x}) \ln (1-\mathrm{x})+\mathrm{x} \ln \gamma_{\mathrm{A}}+(1-\mathrm{x}) \ln \gamma_{\mathrm{B}}\right] \\
& =\mathrm{RT}\left[\mathrm{x} \ln \mathrm{x}+(1-\mathrm{x}) \ln (1-\mathrm{x})+\mathrm{x}(1-\mathrm{x}) \frac{\omega}{\mathrm{k}_{\mathrm{B}} \mathrm{T}}\right]
\end{aligned}
$$

The activity of binary liquid alloys, $\mathrm{a}_{\mathrm{i}}(\mathrm{i}=\mathrm{A}$ or $\mathrm{B})$, is related to the free energy of mixing by the relation

$$
R T \ln a_{i}=\left(\frac{\partial G_{M}}{\partial N_{i}}\right)_{T, P, N}=G_{M}+\left(1-x_{i}\right)\left(\frac{\partial G_{M}}{\partial x_{i}}\right)_{T, P, N}
$$

The activity of the species A and B of the alloys A$B$ obtained respectively from the standard relation equation (10) are :

$$
\ln \mathrm{a}_{\mathrm{A}}=\ln \mathrm{x}+(1-\mathrm{x})^{2} \frac{\omega}{\mathrm{k}_{\mathrm{B}} \mathrm{T}}
$$




$$
\ln a_{B}=\ln (1-x)+x^{2} \frac{\omega}{k_{B} T}
$$

The expression for heat of mixing $\left(\mathrm{H}_{\mathrm{M}}\right)$ is obtained from the standard thermodynamic relation

$$
\begin{aligned}
H_{M} & =G_{M}-T\left(\frac{\partial G_{M}}{\partial T}\right)_{x, P, N} \\
& =R T\left(x(1-x) \frac{\omega}{k_{B} T}-x(1-x) \frac{1}{k_{B}} \frac{\partial \omega}{\partial T}\right)
\end{aligned}
$$

The entropy of mixing $\left(S_{M}\right)$ can easily be worked out from the relation

$$
\mathrm{S}_{\mathrm{M}}=\left(\mathrm{H}_{\mathrm{M}}-\mathrm{G}_{\mathrm{M}}\right) / \mathrm{T}
$$

\section{Structural properties}

The theoretical determination of concentrationconcentration fluctuations in the long-wavelength limit $\left(\mathrm{S}_{\mathrm{cc}}(0)\right)$ is of great importance when nature of interactions in the melt has to be analyzed. $S_{\mathrm{cc}}(0)$ is an essential structural function which has been widely used to study the nature of atomic order in binary liquid alloys (Bhatia \& Hargroove, 1974; Bhatia \& Singh, 1982). It is thermodynamically related to free energy of mixing $\left(\mathrm{G}_{\mathrm{M}}\right)$ through the equation

$$
\mathrm{S}_{\mathrm{cc}}(0)=\mathrm{RT}\left(\frac{\partial^{2} \mathrm{G}_{\mathrm{M}}}{\partial \mathrm{x}^{2}}\right)_{\mathrm{T}, \mathrm{P}, \mathrm{N}}^{-1}
$$

Equations (9) and (15) gives the theoretical value of $\mathrm{S}_{\mathrm{cc}}(0)$ :

$$
S_{c c}(0)=\frac{x(1-x)}{1+z(1-\beta) / 2 \beta}
$$

For the ideal mixing, when the ordering energy is zero, concentration-concentration fluctuations are usually computed from:

$$
\mathrm{S}_{\mathrm{cc}}^{\mathrm{id}}(0)=\mathrm{x}(1-\mathrm{x})
$$

The Warren-Cowley (Warren, 1969; Cowley, 1950) short-range order parameter $\left(\alpha_{1}\right)$ is another important structural function which is useful to quantify the degree of chemical order in the alloy at melt. It provides insight into the local arrangement of the atoms in the molten alloys. Although it is difficult to obtain the experimental values of $\alpha_{1}$, theoretical values of this parameter are easily obtain via conditional probability $[\mathrm{A} / \mathrm{B}]$ which defines the probability of finding an $\mathrm{A}$ - atom as a nearest neighbor of a given B-atom. It can be evaluated theoretically (Warren, 1969; Cowley, 1950):

$$
\alpha_{1}=(\mathrm{S}-1) /\{\mathrm{S}(\mathrm{z}-1)+1\}, \quad \mathrm{S}=\mathrm{S}_{\mathrm{cc}}(0) / \mathrm{S}_{\mathrm{cc}}^{\mathrm{id}}(0)
$$

where $\mathrm{z}$ is the coordination number, which is taken as 10 for our purposes.

\section{Transport properties}

The mixing behavior of binary liquid alloys can also be studied at the microscopic level in terms of transport properties such as chemical diffusion coefficients, viscosity etc. The mutual diffusion coefficient $\left(D_{M}\right)$ of binary liquid alloys can be expressed in terms of activity $\left(a_{i}\right)$ and selfdiffusion coefficient $\left(\mathrm{D}_{\mathrm{id}}\right)$ of pure component with the help of Darken's equation (Darken \& Gurry,1953)

$$
D_{M}=D_{i d} x_{i} \frac{d \ln a_{i}}{d x_{i}}
$$

We obtain an expression for $D_{M}$ in terms of $S_{c c}(0)$ (Singh \& Sommer, 1992):

$$
\frac{D_{M}}{D_{i d}}=\frac{S_{\mathrm{cc}}^{\text {id }}(0)}{S_{\mathrm{cc}}(0)}
$$

with, $\mathrm{D}_{\mathrm{M}}=\mathrm{xD}_{\mathrm{B}}+(1-\mathrm{x}) \mathrm{D}_{\mathrm{A}}$

where $D_{A}$ and $D_{B}$ are the self-diffusion coefficients of pure components $\mathrm{A}$ and $\mathrm{B}$ respectively. Considering only the energetics of the nearestneighbor bond, equation (14) becomes

$$
D_{M}=D_{i d}\left[1-x(1-x)\left(\frac{2 \omega}{k_{B} T}\right)\right]
$$


Viscosity isotherm ( $\eta$ ) of liquid alloys is an important transport parameter for the understanding of the atomic level structure and interactions. As in the case of thermodynamic functions, the composition dependence of $\eta$ of liquid alloys is also found to exhibit either a linear variation, or positive or negative deviations from the linear law. A simple formula for the investigation of viscosity of a binary solution (Moelevyn \& Hughes, 1964) is

$$
\eta=\eta_{i d}\left[1-x(1-x)\left(\frac{2 \omega}{k_{B} T}\right)\right]
$$

with $\eta_{\text {id }}=\mathrm{x} \eta_{\mathrm{A}}^{0}+(1-\mathrm{x}) \eta_{\mathrm{B}}^{0}$

where $\eta_{i}^{0}$ is the viscosity of pure component $i$ ( = $\mathrm{A}$ or $\mathrm{B})$ and $\omega$ as usual, the interchange energy or order energy.

\section{Surface properties}

The knowledge of surface phenomena i.e. surface segregation and surface tension of the alloys can help to explain the technological important various properties such as mechanical behavior, kinetics of phase transformation, catalytic activity of alloy catalyst and thin film etc.
Surface segregation is the enrichment of the surface by the atoms of the particular component element in a binary alloy which results from the interaction among the atoms and surface tension (Prasad \& Singh, 1991). Binary liquid alloy is considered to have a layered structure near the surface with thermodynamic equilibrium existing between the species at the surface and in the bulk (Prasad \& Singh, 1991). The surface properties of liquid alloys are influenced by their bulk thermodynamic properties. The surface grand partition function is related to the surface tension $\tau$ by the expression

$$
\Xi^{\mathrm{s}}=\exp \left(\frac{-\mathrm{S} \tau}{\mathrm{k}_{\mathrm{B}} \mathrm{T}}\right)=\exp \left(\frac{-\mathrm{N}^{\mathrm{s}} \tau \xi}{\mathrm{k}_{\mathrm{B}} \mathrm{T}}\right)
$$

where $\mathrm{S}$ is the surface area and $\xi$ is the mean area of the surface per atom and is defined as $\xi=\mathrm{S} / \mathrm{N}^{\mathrm{s}}$, and $\mathrm{N}^{\mathrm{s}}$ is the total number of atoms at the surface. $\mathrm{k}_{\mathrm{B}}$ is the Boltzmann constant.

A pair of equation for surface tension of the binary liquid alloys in terms of activity coefficient $\left(\gamma_{i}\right)$ of the alloy components and interchange energy parameter $(\omega)$, at the given temperature $T$, proposed by Prasad et al. have been modified in the simple form, using zeroth approximation as

$$
\begin{gathered}
\tau=\tau_{\mathrm{A}}+\frac{\mathrm{k}_{\mathrm{B}} \mathrm{T}}{\xi} \ln \mathrm{x}^{\mathrm{s}}-\frac{\mathrm{k}_{\mathrm{B}} \mathrm{T}}{\xi} \ln \mathrm{x}+\left\{\mathrm{p}\left(1-\mathrm{x}^{\mathrm{s}}\right)^{2}+(\mathrm{q}-1)(1-\mathrm{x})^{2}\right\} \frac{\omega}{\xi} \\
\tau=\tau_{\mathrm{B}}+\frac{\mathrm{k}_{\mathrm{B}} \mathrm{T}}{\xi} \ln \left(1-\mathrm{x}^{\mathrm{s}}\right)-\frac{\mathrm{k}_{\mathrm{B}} \mathrm{T}}{\xi} \ln (1-\mathrm{x})+\left\{\mathrm{p}\left(\mathrm{x}^{\mathrm{s}}\right)^{2}+(\mathrm{q}-1) \mathrm{x}^{2}\right\} \frac{\omega}{\xi}
\end{gathered}
$$

where $\tau_{\mathrm{A}}$ and $\tau_{\mathrm{B}}$ are the surface tension values for the pure components $\mathrm{A}$ and $\mathrm{B}$ respectively; $\mathrm{X}$ and $x^{\mathrm{s}}$ are the bulk and surface concentrations of the alloy component; $\mathrm{p}$ and $\mathrm{q}$ are the surface coordination fractions, which are defined as the fraction of the total number of nearest neighbors made by atom within its own layer and that in the adjoining layer. For $\mathrm{p}$ and $\mathrm{q}$, the following relation is available (Prasad \& Singh, 1991).

$P+2 q=1$
For closed packed structure, $p=0.5$ while $q=0.25$ (in view of the disordered structure and relaxation effect of the surface layer $p$ and $q$ should be treated as parameters (Prasad \& Singh, 1991; Novakovic, 2010)).

The pair of equation 17 (a) and 17 (b) can be solved numerically to obtain $\mathrm{x}^{\mathrm{s}}$ as a function of $\mathrm{x}$. Obviously the surface concentration depends upon the surface tension of the ith component in the pure state $\left(\tau_{\mathrm{i}}\right)$, surface area per atom $(\xi)$, order energy $(\omega)$ and the coordination fractions (p and $q$ ). This approach is useful because it can be used to investigate the dependence of surface composition on order energy and surface coordination. 
The mean atomic surface area $\xi\left(=\mathrm{A} / \mathrm{N}^{\mathrm{s}}\right)$ is given as

$$
\xi=\sum \mathrm{x}_{\mathrm{i}} \xi_{\mathrm{i}} \quad(\mathrm{i}=\mathrm{A}, \mathrm{B})
$$

Where the atomic area of hypothetical surface for each component is given as (Prasad \& Singh,1991):

$$
\xi_{\mathrm{i}}=1.102\left(\Omega_{\mathrm{i}} / \mathrm{N}_{0}\right)^{2 / 3}
$$

where $\Omega_{\mathrm{i}}$ is the molar volume of the species $\mathrm{i}$ and $\mathrm{N}_{0}$ stands for Avogadro number.

On the basis of assumption of monatomic surface layer, Butler's approach (Butler, 1932) of surface tension $\tau$ of liquid solution can be expressed as

$$
\tau=\frac{\mu_{\mathrm{A}}^{\mathrm{s}}-\mu_{\mathrm{A}}^{\mathrm{b}}}{\alpha_{\mathrm{A}}}=\frac{\mu_{\mathrm{B}}^{\mathrm{s}}-\mu_{\mathrm{B}}^{\mathrm{b}}}{\alpha_{\mathrm{B}}}=\ldots \ldots=\frac{\mu_{\mathrm{i}}^{\mathrm{s}}-\mu_{\mathrm{i}}^{\mathrm{b}}}{\alpha_{\mathrm{i}}}
$$

Where $\mu_{\mathrm{i}}^{\mathrm{s}}, \mu_{\mathrm{i}}^{\mathrm{b}}$ and $\alpha_{\mathrm{i}}$ represent respectively the chemical potential in the hypothetical surface and that in the bulk and molar surface area of pure component i (A or B).

Equation (23) yields the expressions for surface tension in terms of partial excess free energy of mixing in bulk $\left(G_{i}^{E, b}\right)$ and at the surface $\left(G_{i}^{E, s}\right)$ and concentration in the bulk $(\mathrm{x})$ and at the surface $\left(\mathrm{x}^{\mathrm{s}}\right)$ as

$$
\begin{aligned}
& \tau=\tau_{A}+\frac{1}{\alpha_{A}}\left(G_{A}^{E, s}-G_{A}^{E, b}\right)+\frac{R T}{\alpha_{A}} \operatorname{Inx} s-\frac{R T}{\alpha_{A}} \operatorname{Inx} \\
& \tau=\tau_{B}+\frac{1}{\alpha_{B}}\left(G_{B}^{E, s}-G_{B}^{E, b}\right)+\frac{R T}{\alpha_{B}} \operatorname{In}\left(1-x^{s}\right)-\frac{R T}{\alpha_{B}} \operatorname{In}(1-x)
\end{aligned}
$$

where $\tau_{\mathrm{A}}$ and $\tau_{\mathrm{B}}$ are surface tension of pure component $\mathrm{A}$ and $\mathrm{B}$ respectively.

The area of monatomic surface layer for the component i can be calculated by the relation (Butler, 1932)

$$
\alpha_{\mathrm{i}}=1.091 \mathrm{~N}_{0}^{1 / 3} \Omega_{\mathrm{i}}^{2 / 3}
$$

Where $\mathrm{N}_{0}$ is Avogadro's number and $\Omega_{\mathrm{i}}$ stands for molar volume of the component i, can be calculated from its molar mass and density.

In order to compare the behavior of concentration- concentration fluctuations and Warren-Cowley short rang order parameter in the bulk and at the surface of the alloys, we need an expression for determination of concentrationconcentration fluctuations and warren-Cowley short rang order parameter at the surface. On the basis of earlier works of Singh et al. in ref (Singh \& Sommer, 1992) for the bulk phase, an expression for concentration- concentration fluctuations at the surface obtained via solving the surface grand partition function is given by (Singh \& Sommer, 1992; Anusionwu et al., 1998)

$$
\mathrm{S}_{\mathrm{cc}}^{\mathrm{s}}(0)=\frac{\mathrm{x}^{\mathrm{s}}\left(1-\mathrm{x}^{\mathrm{s}}\right)}{1+\mathrm{z}^{\mathrm{s}}\left(1-\beta^{\mathrm{s}}\right) / 2 \beta^{\mathrm{s}}}
$$

with

$\beta^{\mathrm{s}}=\left\{1+4 \mathrm{x}^{\mathrm{s}}\left(1-\mathrm{x}^{\mathrm{s}}\right)\left[\exp \left(2 \omega / \mathrm{z}^{\mathrm{s}} \mathrm{k}_{\mathrm{B}} \mathrm{T}\right)-1\right]\right\}^{1 / 2}$

Here $z^{\mathrm{s}}$ is the coordination number of surface atoms which is obtained from $z^{\mathrm{s}}=(\mathrm{p}+\mathrm{q}) \mathrm{z}$ and $\mathrm{z}$ is the coordination number in bulk. In the case of ideal mixing (i.e. $\omega=0$ ), equation (21) reduces to

$$
\mathrm{S}_{\mathrm{cc}}^{\mathrm{s}}(0, \text { ideal })=\mathrm{x}^{\mathrm{s}}\left(1-\mathrm{x}^{\mathrm{s}}\right)
$$

The expression for the surface Warren-Cowley short range order parameter, deduced from equation (11) is given by

$$
\alpha_{1}^{\mathrm{S}}=\left(\mathrm{S}^{\mathrm{S}}-1\right) /\left\{\mathrm{S}^{\mathrm{S}}\left(\mathrm{z}^{\mathrm{S}}-1\right)+1\right\}, \quad \mathrm{S}^{\mathrm{S}}=\mathrm{S}_{\mathrm{cc}}^{\mathrm{S}}(0) / \mathrm{x}^{\mathrm{S}}\left(1-\mathrm{x}^{\mathrm{S}}\right)
$$




\section{RESULTS AND DISCUSSION}

\section{Thermodynamic properties}

\section{Free energy of mixing}

There are large numbers of binary liquid alloys whose concentration dependent properties of mixing are symmetric around equi-atomic composition, which are called regular alloys. The simple statistical model has been used to explain the symmetry in concentration dependence of free energy of mixing of regular alloys $\mathrm{Ag}-\mathrm{Au}$ in the molten state. For the computation of free energy of mixing, the basic input parameter is interchange or order energy $(\omega)$. It may be noted that once the parameter is determined, this remains the same for other investigations such as structural, transport and surface properties. Using equation (9), such energy parameter $\left(\frac{\omega}{\mathrm{k}_{\mathrm{B}} \mathrm{T}}\right)$ has been determined by the method of successive approximation and comparing the results with the experimental values (Hultgren et al., 1973) of free energy of mixing till the best fit parameter is obtained. The best fit value of energy parameter for the calculation for $\mathrm{Ag}-\mathrm{Au}$ liquid alloys at $1350 \mathrm{~K}$ is found as

$\frac{\omega}{\mathrm{k}_{\mathrm{B}} \mathrm{T}}=-0.892$

The negative value of energy parameter indicates that the species atoms $\mathrm{Ag}$ and $\mathrm{Au}$ in $\mathrm{Ag}-\mathrm{Au}$ system are attracted to each other and suggests that there is higher tendency for unlike atoms to pair in the alloys which imply a hetero-coordination system. However, the tendency of pairing is weak since energy parameter is small.

Using equation (9), we have computed the free energy of mixing of $\mathrm{Ag}-\mathrm{Au}$ liquid alloys at $1350 \mathrm{~K}$ in the concentration range of $x_{\mathrm{Ag}}=0.1$ to 0.9 . The computed and experimental values of $\mathrm{G}_{\mathrm{M}}$ against concentration of silver are plotted in figure 1 . The computed and experimental values of $\mathrm{G}_{\mathrm{M}}$ are in good agreement throughout whole concentration of silver. The computed minimum value of $G_{M}$ is $0.9161 \mathrm{RT}$ at $\mathrm{x}_{\mathrm{Ag}}=0.5$ which is very close to experimental minimum value $(=-0.9159 \mathrm{RT})$ at the same concentration of silver, which show that Ag$\mathrm{Au}$ liquid alloys is symmetric about equi-atomic concentration. The negative small values of free energy of mixing throughout the entire compositions indicate that the $\mathrm{Ag}-\mathrm{Au}$ alloys at $1350 \mathrm{~K}$ in molten state is weakly interacting system.

\section{Chemical activity}

The activity is one of the important thermodynamic functions which are obtained directly from experiment. The deviation from ideal behavior is incorporated into activity. We have used the same value of the energy parameter in equation (11) and (12) for the evaluation of chemical activities of the components of the alloys. There is well agreement between computed and experimental values of the activities of the components $\mathrm{Ag}$ and $\mathrm{Au}$ of the alloys (Figure 1). Therefore our choice of $\omega$ for the alloy is good because it is confirmed from the qualitative agreement between computed and experimental values.

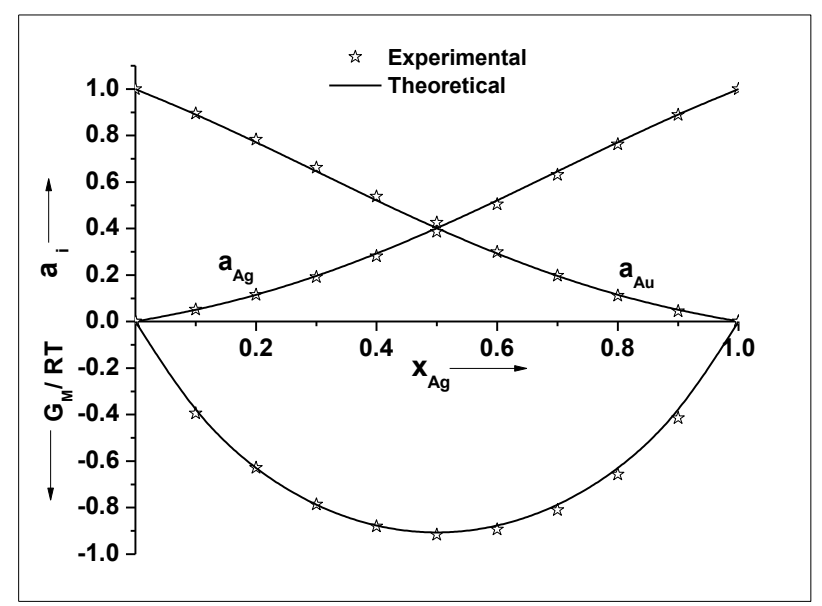

Fig.1. Free energy of mixing $\left(G_{M} / R T\right)$ and activity $\left(a_{i}\right)$ as a function of concentration of silver $\left(x_{A g}\right)$ for alloys $\mathrm{Ag}-\mathrm{Au}$ in the molten state at $1350 \mathrm{~K}$.

\section{Heat of mixing}

To determine the heat of mixing for liquid $\mathrm{Ag}-\mathrm{Au}$ alloys, we need temperature derivative of interchange energy. By using successive approximation method, the observed values of $\mathrm{H}_{M}$ [Hultgren et al.,1973] are used in equation (13) to obtain the temperature derivative of interchange energy. The best fit value of the parameter is found to be

$$
\frac{1}{\mathrm{~K}_{\mathrm{B}}} \frac{\partial \omega}{\partial \mathrm{T}}=+0.942
$$

If the interchange energy is supposed to be independent of temperature, i.e. $\frac{\partial \omega}{\partial T}=0$, then computed values of $\mathrm{H}_{\mathrm{M}}$ are found to be very poor agreement with experimental data (Hultgren et al., 1973). But the introduction of temperature 
derivative of interchange energy leads to a better agreement between computed and observed data of Hultgren et al. (1973). This simply suggests importance of the dependence of interchange energy on temperature. We have computed the heat of mixing by using equation (13) with the help of input parameters from equations (39) and (40). The plot of computed values of heat of mixing and corresponding experimental values against concentrations of silver is shown in figure (2). The figure shows that the computed and experimental values of $\mathrm{H}_{\mathrm{M}}$ are in well agreement in the whole concentration range of silver. It is found from the analysis that $\mathrm{H}_{\mathrm{M}}$ for $\mathrm{Ag}-\mathrm{Au}$ system is negative at all concentration and is minimum $(=-0.4585 \mathrm{RT})$ at $\mathrm{x}_{\mathrm{Ag}}=0.5$ which exactly matches with the experimental minimum value at the same concentration of silver.

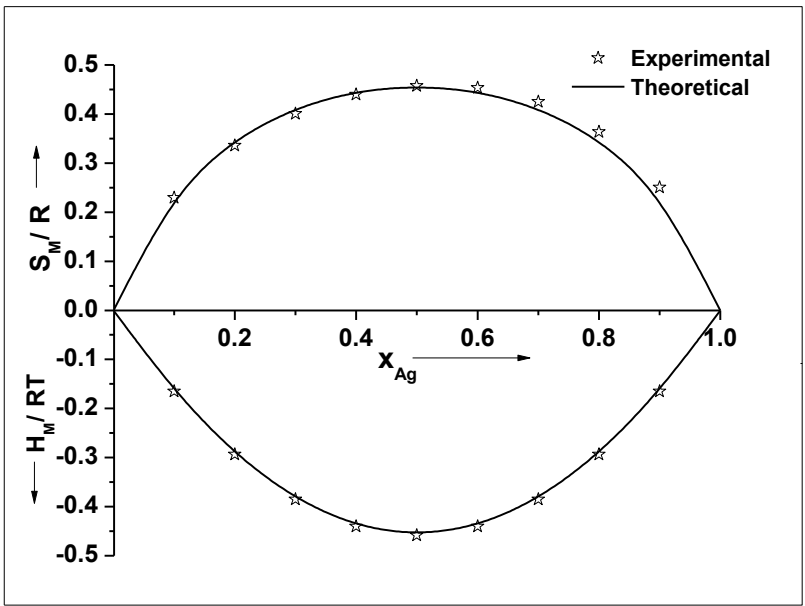

Fig.2. Heat of mixing $\left(H_{M} / R T\right)$ and entropy of mixing $\left(S_{M} / R\right)$ as a function of silver $\left(x_{A g}\right)$ for alloys $\mathrm{Ag}-\mathrm{Au}$ in the molten state at $1350 \mathrm{~K}$.

\section{Entropy of mixing}

Using equation (14) entropy of mixing for liquid $\mathrm{Ag}-\mathrm{Au}$ alloys at $1350 \mathrm{~K}$ is computed. The plot of entropy of mixing verses concentration of $\mathrm{Ag}$ is depicted in figure (2), for both the computed and observed values. The figure shows that theoretical values of $S_{M}$ are in good agreement along with the experimental values (Hultgren et al., 1973).

\section{Structural properties}

The concentration-concentration fluctuation in long wavelength limit and Warren-Cowley short range order parameter

The mixing behavior of liquid alloys can be deduced from the deviation of concentrationconcentration fluctuations at long wavelength limit
$\left(S_{\mathrm{cc}}(0)\right)$ from $S_{\mathrm{cc}}^{\mathrm{id}}(0)$. At a given composition if $\mathrm{S}_{\mathrm{cc}}(0)<\mathrm{S}_{\mathrm{cc}}^{\mathrm{id}}(0)$, ordering in liquid alloy is expected while $\mathrm{S}_{\mathrm{cc}}(0)>\mathrm{S}_{\mathrm{cc}}^{\mathrm{id}}(0)$ gives the indication of tendency of segregation.

We have used equation (16) to compute the $S_{c c}(0)$ for $\mathrm{Ag}-\mathrm{Au}$ system. It can also be obtained directly from the measured activity (Hultgren et al., 1973) data as

$\mathrm{S}_{\mathrm{cc}}(0)=(1-\mathrm{x}) \mathrm{a}_{\mathrm{Ag}}\left(\frac{\partial \mathrm{a}_{\mathrm{Ag}}}{\partial \mathrm{x}}\right)^{-1}=\mathrm{xa}_{\mathrm{Au}}\left(\frac{\partial \mathrm{a}_{\mathrm{Au}}}{\partial(1-\mathrm{x})}\right)^{-1}$

where $a_{A g}$ and $a_{A u}$ are the observed chemical activities of silver and gold respectively. The $\mathrm{S}_{\mathrm{cc}}(0)$, obtained from equation (41) are taken as experimental values. Figure 3 shows a plot of the computed and experimental values of $\mathrm{S}_{\mathrm{cc}}(0)$ along with the ideal values as a function of concentration. The computed values of $\mathrm{S}_{\mathrm{cc}}(0)$ are in good agreement with the experimental values of $\mathrm{S}_{\mathrm{cc}}(0)$ in the region $0.4 \square \mathrm{x}_{\mathrm{Ag}} \leq 0.9$. In the region $0.1 \leq \mathrm{x}_{\mathrm{Ag}} \leq 0.4$, the computed values just lie below the experimental values but in the whole range of concentrations of silver, computed values of $\mathrm{S}_{\mathrm{cc}}(0)$ lying below the corresponding ideal values. The result $\mathrm{S}_{\mathrm{cc}}(0)\left\langle\mathrm{S}_{\mathrm{cc}}^{\mathrm{id}}(0)\right.$, clearly described this system as compound forming.

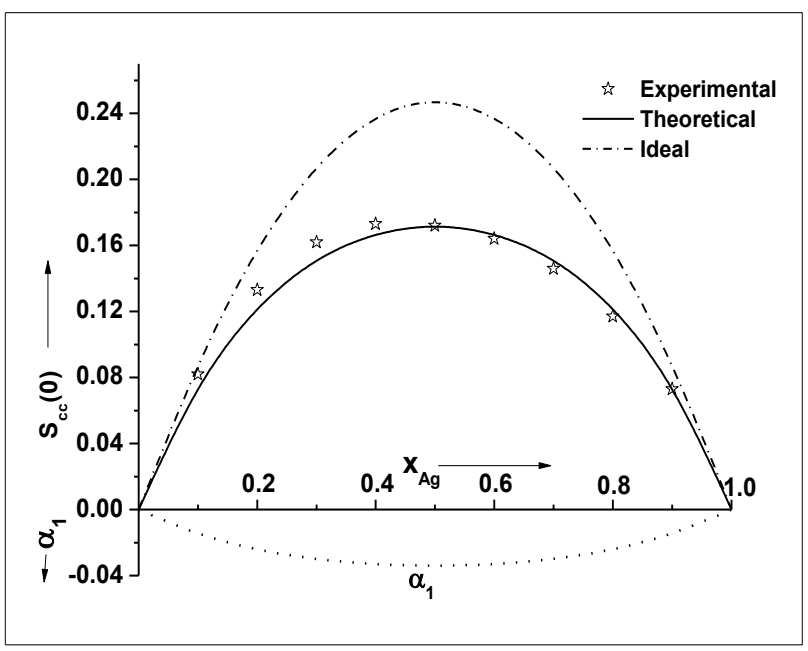

Fig.3. Concentration fluctuation in long wavelength limit $\left(S_{c c}(0)\right)$ and Warren-Cowley short range order parameter $\left(\alpha_{1}\right)$ as a function of concentration of silver $\left(x_{A g}\right)$ for alloys $\mathrm{Ag}-\mathrm{Au}$ in the molten state at $1350 \mathrm{~K}$. 
Figure 3 also shows the plot of Warren-Cowely chemical short range order parameter $\left(\alpha_{1}\right)$ against chemical composition of silver, obtained from equation (18) for $\mathrm{Ag}-\mathrm{Au}$ at $1350 \mathrm{~K}$. For the equiatomic composition, $\alpha_{1}$ is found to be $-1 \leq \alpha_{1} \leq 1$. Negative values of $\alpha_{1}$ indicate ordering in the melt, which is complete if $\alpha_{1}=-1$. On the other hand, positive values of $\alpha_{1}$ indicate segregation, leading to complete only if $\alpha_{1}=1$. But $\alpha_{1}=0$, corresponds to random distribution of the atoms in the mixture. It is observed that the plot is symmetrical about equiatomic composition and negative throughout the whole concentration range of silver. The negative values of $\alpha_{1}$ (minimum at $\mathrm{x}_{\mathrm{Ag}}=0.5$ ) throughout whole concentration range are the signatures of hetero-coordination system in the $\mathrm{Ag}$-Au liquid alloys at $1350 \mathrm{~K}$.

\section{Transport properties}

The computed values of $S_{c c}(0)$ are used in Eq. (20) to evaluate the ratio of the mutual and intrinsic-diffusion coefficients, $D_{M} / D_{i d}$. For the consistency of the estimated order energy, $\omega$, we have also calculated $D_{M} / D_{\text {id }}$ using equation (22). According to Eq. (20), $\mathrm{S}_{\mathrm{cc}}(0)\left\langle\mathrm{S}_{\mathrm{cc}}^{\mathrm{id}}\right.$ is typical compound forming alloys implying $\mathrm{D}_{\mathrm{M}} \square \mathrm{D}_{\text {id }}$. A peak on diffusivity curve, $D_{M} / D_{i d}$ verses concentration, suggests presence of maximum chemical order in the molten alloys system as well as the composition of the most probable associates formed in the liquid phase (Singh \& Sommer, 1992). The relationship between $S_{c c}(0)$ and the diffusivity expressed by the ratio of the mutual and self-diffusion coefficients, $D_{M} / D_{\text {id }}$, indicates the mixing behavior of the alloys, i.e. the tendency for compound formation $\left(D_{M} / D_{i d}>\right.$ 1) or phase separation $\left(D_{M} / D_{\text {id }}<1\right)$ or ideal mixing $\left(D_{M} / D_{i d}\right.$ approaches 1$)$. Figure 5 shows plot of $D_{M} / D_{\text {id }}$ against the concentration of silver. In that plot the value of $D_{M} / D_{i d}$ is found greater than 1 in the entire range of concentration which is indicative for the compound formation in the mixture. A maximum value of $D_{M} / D_{i d}=$ 1.446 for $\mathrm{x}_{\mathrm{Ag}}=0.5$, confirms a weak tendency for chemical ordering, as observed by the $S_{c c}(0)$ and CSRO parameter. The viscosity of liquid $\mathrm{Ag}-\mathrm{Au}$ alloys has been computed numerically from equation (23). From the plot of viscosity verses bulk concentration of $\mathrm{x}_{\mathrm{Ag}}$ (Figure 4) in $\mathrm{Ag}-\mathrm{Au}$ system, positive deviation from the linear law (Raoult's law) in viscosity isotherms $\eta(c)$ have been observed for the regular alloy.

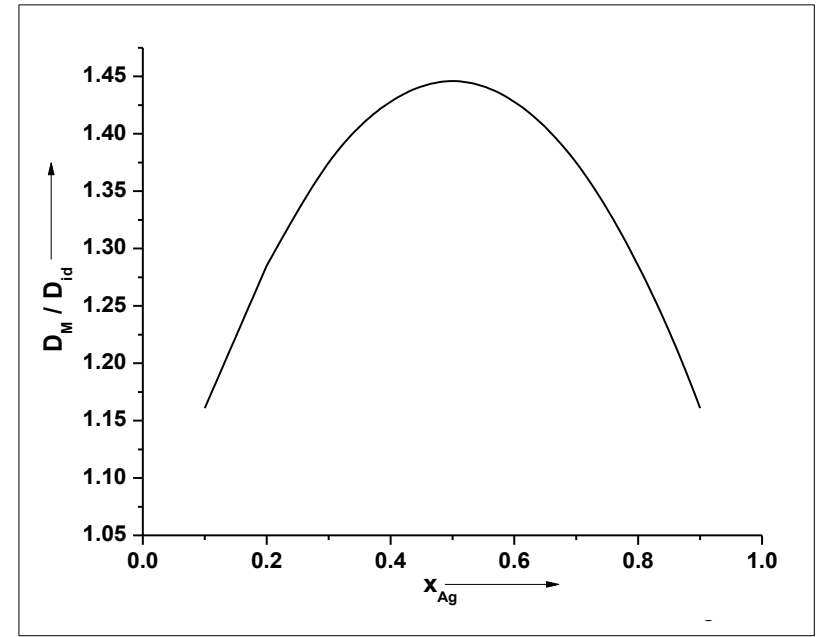

Fig.4. Diffusion coefficient ratio $\left(D_{M} / D_{i d}\right)$ as a function of concentration of silver $\left(x_{A g}\right)$ for alloys $\mathrm{Ag}-\mathrm{Au}$ in the molten state at $1350 \mathrm{~K}$.

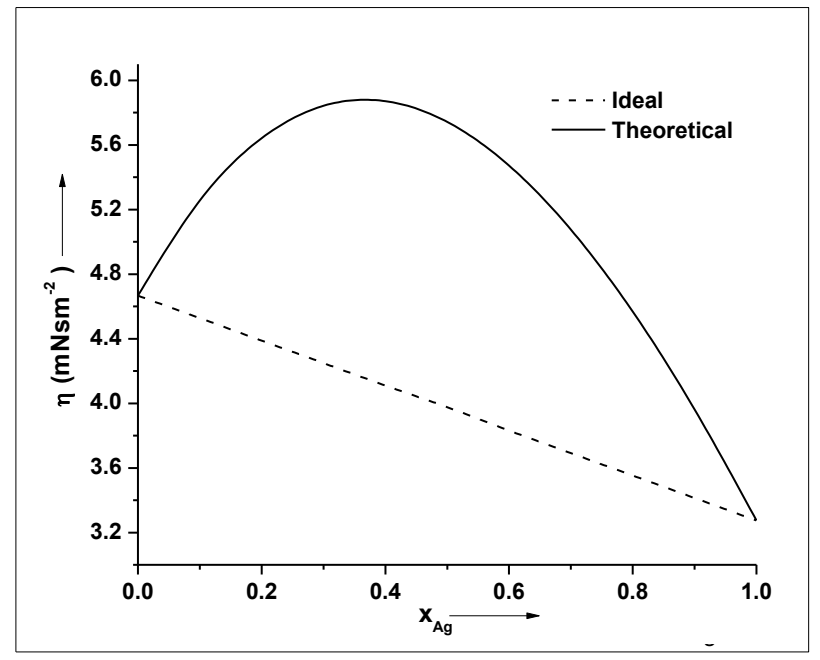

Fig.5. Viscosity ( $\square$ ) as a function of concentration of silver $\left(x_{A g}\right)$ for alloys $A g-A u$ in the molten state at $1350 \mathrm{~K}$.

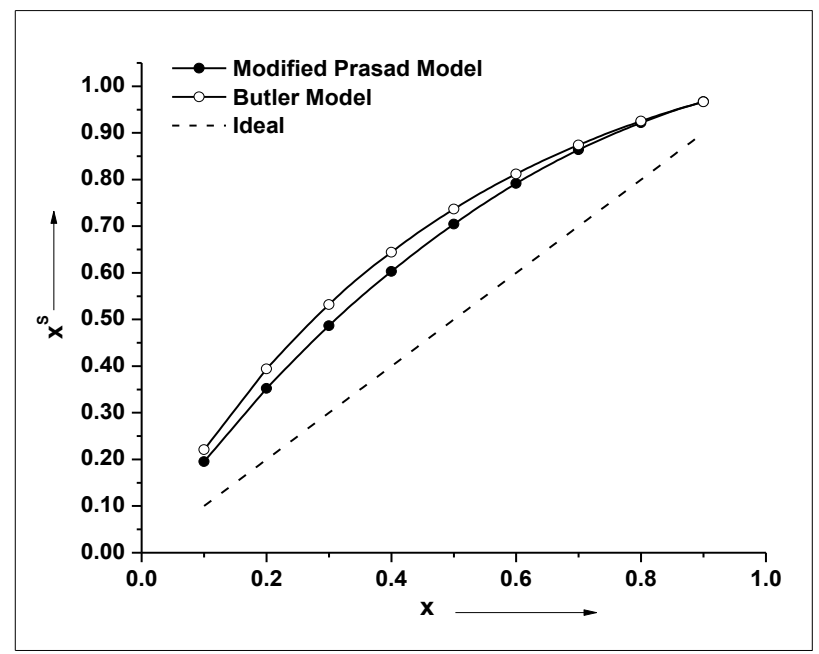

Fig.6. Surface concentration $\left(x^{s}\right)$ as a function of bulk concentration of silver (x) for alloys Ag-Au in the molten state at $1350 \mathrm{~K}$. 


\section{Surface properties}

The surface concentrations and surface tension of $\mathrm{Ag}-\mathrm{Au}$ have been computed numerically from the equation (26) and (27). For this, we need experimental data of density and surface tension of the components at the working temperature. The density and surface tension for the components $\mathrm{Ag}$ and $\mathrm{Au}$ (Brandes \& Smithells, 1983; Iida \& Guthrie, 1988) at the working temperature $\mathrm{T}=1350 \mathrm{~K}$ have been calculated by using the following equations

$$
\begin{aligned}
& \rho_{A g}(T)=10.46-9.07 \times 10^{-4} \mathrm{~T} \\
& \rho_{\mathrm{Au}}(T)=19.30-15.00 \times 10^{-4} \mathrm{~T} \\
& \tau_{\mathrm{Ag}}(\mathrm{T})=1.10-1.6 \times 10^{-4} \mathrm{~T} \\
& \tau_{\mathrm{Au}}(\mathrm{T})=1.83-5.2 \times 10^{-4} \mathrm{~T}
\end{aligned}
$$

The mean atomic surface area $\xi$ has been calculated by using equations (29) and (30). For calculating surface tension we used same estimated energy parameter, $\omega$. At first, surface concentrations of silver in alloys $\mathrm{Ag}-\mathrm{Au}$ have been obtained as a function of bulk concentration by concurrently solving the equations (26) and (27). Using the obtained values of surface concentrations we computed the surface tension of $\mathrm{Ag}-\mathrm{Au}$ liquid alloys at temperature $1350 \mathrm{~K}$ for whole concentration range.

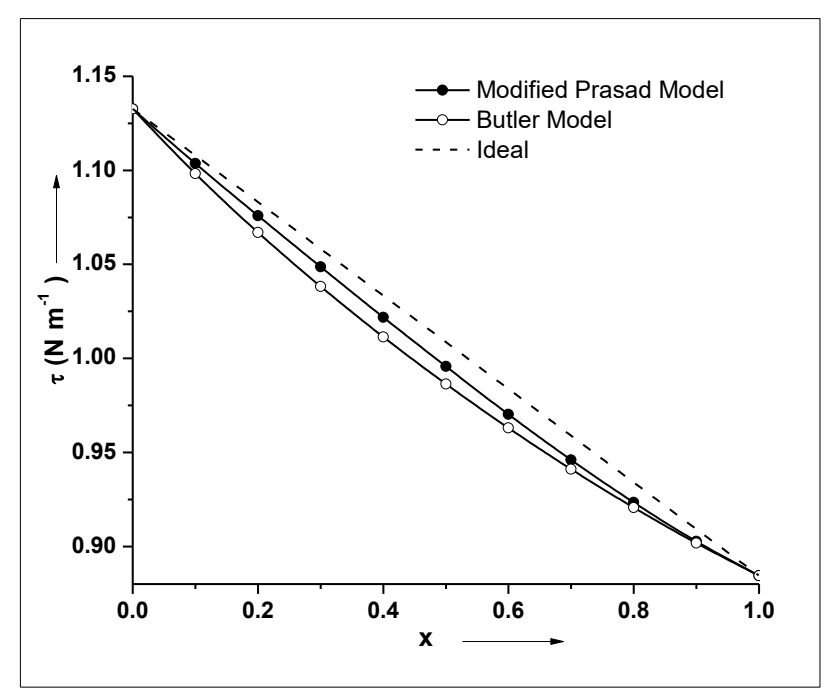

Fig.7. Surface tension ( $\tau$ ) as a function of bulk concentration of silver $(x)$ for alloys $A g-A u$ in the molten state at $1350 \mathrm{~K}$.
For the computation of surface concentration and surface tension of the Ag-Au alloys on using Butler's approach, the partial excess free energies of mixing of pure components of the alloys have been taken from the ref. (Hultgren et al., 1973). By concurrently solving the equations (32) and (33) surface concentrations of $\mathrm{Ag}$ in alloys $\mathrm{Ag}-\mathrm{Au}$ have been obtained as a function of bulk concentration and then using the obtained values of surface concentrations we computed the surface tension of $\mathrm{Ag}$-Au liquid alloys at temperature $1350 \mathrm{~K}$ for whole concentration range. The study of surface concentration as shown in figure 6 shows the usual pattern for surface concentration increasing with increasing bulk compositions. This indicates that Ag-atoms (having lower value of surface tension relative to $\mathrm{Au}$-atoms in $\mathrm{Ag}-\mathrm{Au}$ ) segregate at the surface of $\mathrm{Ag}-\mathrm{Au}$ liquid alloys in preference to Au-atoms throughout the entire compositions. The computed values of surface tension for molten $\mathrm{Ag}-\mathrm{Au}$ alloys at $1350 \mathrm{~K}$ from both approaches, mentioned above are depicted in figure 7. Due to lack of surface tension experimental data we could not compare our computed surface tension with the experimental data, nonetheless, we observed that the isothermal plots of surface tension of the system exhibits negative deviation from the ideal values $\left(\tau=\tau_{\mathrm{A}} \mathrm{x}+\tau_{\mathrm{B}}(1-\mathrm{x})\right)$ as it is the case with most binary liquid mixtures (Hultgren et al.,1973). It is noticed that computed values of $\tau$ and $x_{\mathrm{Ag}}^{\mathrm{S}}$ are found to be smaller than the ideal values throughout bulk concentration of silver.

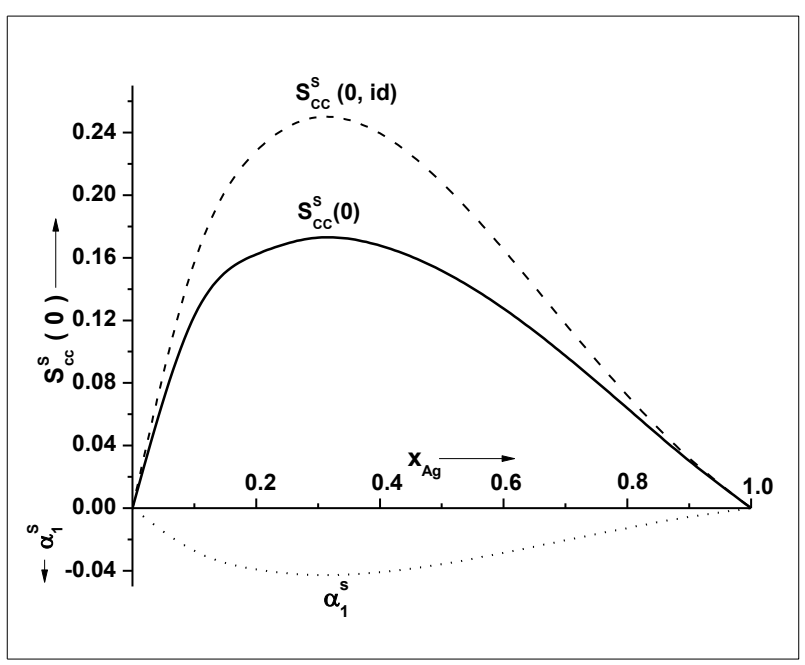

Fig.8. Surface concentration fluctuation in long wavelength limit $\left(S_{c c}{ }^{s}(0)\right)$ and surface WarrenCowley short range order parameter $\left(\alpha_{1}^{s}\right)$ as a function of concentration of silver $\left(x_{A g}\right)$ for alloys $\mathrm{Ag}-\mathrm{Au}$ in the molten state at $1350 \mathrm{~K}$. 
The absence of irregularities in the form of minimum, maximum or inflection point in the isothermal plots of the surface tension of the alloys $\mathrm{Ag}-\mathrm{Au}$ is a signature of the absence of stoichiometric intermetallic compound formation in the system. To predict the local order on the surface of the liquid alloys, the surface concentrationconcentration fluctuations, $S_{\mathrm{cc}}^{\mathrm{s}}(0)$ and surface warren-Cowley short range order parameter, $\alpha_{1}^{\mathrm{s}}$ was computed through equation (35) and (38) and plotted against the bulk concentrations of silver of the alloys in figure 8 . The figure 8 shows that $\mathrm{S}_{\mathrm{cc}}^{\mathrm{s}}(0)$ and $\mathrm{S}_{\mathrm{cc}}^{\mathrm{s}}(0, \mathrm{id})$ for the alloys are skewed towards the lower concentrations of silver. However just as in figure 3, figure 8 shows $\mathrm{S}_{\mathrm{cc}}^{\mathrm{s}}(0)<$ $S_{\mathrm{cc}}^{\mathrm{s}}(0$, id $)$ throughout the entire composition of silver in Ag-Au which indicates the presence of chemical order both in bulk and on the surface of the liquid alloys. In Fig.8, $\alpha_{1}^{\mathrm{s}}$ is skewed towards the lower concentrations of silver and just like bulk $\alpha_{1}$, surface warren-Cowley short range order parameter is negative throughout all concentrations of silver.

\section{CONCLUSIONS}

The analysis reveals that there is a tendency of unlike atom pairing or hetero-coordination $(\mathrm{Ag}-\mathrm{Au}$, $\mathrm{Au}-\mathrm{Ag})$ in liquid $\mathrm{Ag}-\mathrm{Au}$ alloys at all concentrations. The theoretical analysis suggests that this alloy is of a weakly interacting nature. Thermodynamic and structural functions are deviated negatively from the linear law. In case of viscosity isotherms, positive deviation from ideality is observed but surface tension isotherms of $\mathrm{Ag}-\mathrm{Au}$ alloys are deviated negatively from their ideal values. Theoretical study proofs that metal with lower surface tension tends to segregate on the surface of molten alloys. The smaller Au-atoms segregate in the bulk but bigger Ag-atoms segregate at the surface of liquid $\mathrm{Ag}$-Au alloys. In the overall calculations, interchange energy takes an important role which is concentration independent but dependent of temperature.

\section{ACKNOWLEDGEMENT}

Author is grateful to Dr. Devendra Adhikari (Professor, M. M. A. M. Campus Biratnagar, Tribhuvan University, Nepal), Dr. Lok Narayan Jha and Dr. Shekhar Gurung (Retired Professor, Tribhuvan University, Nepal) for fruitful suggestions and inspiring discussions.

\section{REFERENCES}

Akinlade, O. and Singh, R. N. (2002). Bulk and surface properties of liquid $\mathrm{In}-\mathrm{Cu}$ alloys. $J$. Alloys and Compounds, 333: 84-90.

Andrews, D. R. (1978). Soldering, brazing, welding and adhesives. Institution of production engineers, London.

Anusionwu, B. C.; Akinlade, O.; Hussain L. A. (1998). Assessment of size effects on the surface properties of binary liquid alloys. Journal of Alloys Compounds, 175: 278-181.

Bhatia, A. B. and Singh, R. N. (1982). Thermodynamic Properties of Compound Forming Molten Alloys in a Weak Interaction Approximation. Phys. Chem. Liq., 11 (4): 343-351.

Bhatia, A. B.; Hargoove, W. H. (1974). Concentration fluctuations and thermodynamic properties of some compound forming binary molten system. Phys. Rev. B, 10 (5): 3186-3196.

Brandes E. A. and Smithells (1983). Metals Reference Book, Sixth Edition, Sec.14-6.

Butler, J. A. V. (1932). The thermodynamics of the surfaces of solutions. Proc. R. Soc. A., 135: 384.

Cowley, J. M. (1950). An Approximate Theory of Order in Alloys. Phys. Rev., 77: 669.

Darken, L. S. and Gurry R. W. (1953). Physical Chemistry of Metals. McGraw Hill, New York, pp. 535.

Ghimire, M. P.; Kaphle, G. C.; Thapa, R. K. (2016). Electronic and Magnetic Properties of Double Perovskites Nd2MgIrO6. Journal of Nepal Physical Society, 3 (1): 50-54.

Guggenheim, E. A. (1952). Mixtures. Oxford University Press. London. http://www.keytometals.com.

Hultgren, R.; Desai, P. D.; Hawkins, D. T.; Gleiser, M.; Kelley, K. K. (1973). Selected Values of the Thermodynamic Properties of Binary Alloys. ASM Metals Park, Ohio. 1013.

Iida, T. and Guthrie, R. I. L. (1988). The physical properties of liquid metals. Clarendon Press; Oxford. Journal of Non-Crystalline Solids, 61-62: 279.

Jha, I. S.; Koirala, I.; Singh, B. P.; Adhikari, D. (2014). Concentration dependence thermodynamic, transport and surface properties in $\mathrm{Ag}-\mathrm{Cu}$ liquid alloys. Applied Physics A., 116 (3): 1517-1523. 
Jha, I. S.; Singh, B. P. and Koirala, I. (2014). Theoretical assessment on segregating nature of liquid In-Tl alloys. J. Non. Cryst. Solids, 398-399: 26-31.

Kaphle, G. C., Adhikari, N. P., and Mookerjee, A. (2015). Study of spin glass behavior of disordered $\mathrm{Pt}_{\mathrm{X}} \mathrm{Mn}_{(1-\mathrm{X})}$ alloys: An Augmented space recursion Approach. Advanced Science Letters, 21 (9): 2681.

Kaphle, G. C.; Ganguly, S.; Banerjee R.; Khanal R.; Adhikari, C. M. ; Adhikari, N. P. and Mookerjee, A. (2012). Study of Magnetism in disordered Pt-Mn, Pd-Mn and Ni-Mn alloys: An augmented space approach. Journal of Physics, 24: 295501.

Koirala, R. P.; Singh, B. P.; Jha, I. S. and Adhikari D. (2013). Thermodynamic, structural and surface properties of liquid $\mathrm{Cd}-\mathrm{Zn}$ alloys. $J$. Molecular Liquids, 60: 179.

Kumar, A.; Jha, I. S.; Singh, B. P. (2013). Thermodynamics and atomic order in molten Mg-Bi alloys. Adv. Matt. Lett. 4 (2): 155159.

Moelevyn-Hughes, E. A. (1964). Physical chemistry. Oxford, Pergamon.

Novakovic, R. (2010). Thermodynamics, surface properties and microscopic functions of liquid $\mathrm{Al}-\mathrm{Nb}$ and $\mathrm{Nb}-\mathrm{Ti}$ alloys. J. Non-Cryst. Solids. 356: 1593-1598.

Pandey, B.; Ray, R. B. and Kaphle, G. C. (2017). First-principles study of structural, electronic and magnetic properties of Co-based quaternary Heusler compounds: $\mathrm{CoFeCrAl}$, CoFeTiAs, $\mathrm{CoFeCrGa}$ and CoMnVAs. BIBECHANA, 15: 50-59.

Pandey, S.; Kaphle, G. C. and Adhikari, N. P. (2014). Electronic structure and magnetic properties of bulk elements ( $\mathrm{Fe}$ and $\mathrm{Pd}$ ) and ordered binary alloys ( $\mathrm{FePd}$ and $\mathrm{Fe}_{3} \mathrm{Pd}$ ):TBLMTO Approach. BIBECHANA, 11: 60.

Poudel, R. and Kaphle, G. C. (2016). Study of electronic and magnetic properties of $\mathrm{Fe}, \mathrm{Cr}$, $\mathrm{FeCr}$ and $\mathrm{FeCr}_{3}$ : TB-LMTO Approach. Patan Gyan Sagar, 2 (1): 80.

Prasad, L. C. and Singh R. N. (1991). Surface segregation and concentration fluctuations at the liquid-vapour interface of molten $\mathrm{Cu}-\mathrm{Ni}$ alloys. Phys. Rev. B. 44 (24): 13768-13771.

Prasad, L. C.; Singh, R. N.; Singh, V. N.; Singh G. P. (1998). Correlation between bulk and surface properties of Ag-Sn liquid alloys. $J$. Phys. Chem. B. 102: 921-926.

Sedhain, R. P. and Kaphle, G. C. (2017). Structural and Electronic Properties of Transition Metal Di-chalcogenides $\left(\mathrm{MX}_{2}\right) \mathrm{M}=(\mathrm{Mo}, \mathrm{W})$ and $\mathrm{X}=(\mathrm{S}, \mathrm{Se})$ in Bulk State: a First-principles Study. Journal of Institute of Science and Technology, 22 (1): 41-50.

Sharma, P. and Kaphle, G. C. (2017). Electronic and Magnetic Properties of Half Metallic Heusler Alloy Co2MnSi: A First-Principles Study. Journal of Nepal Physical Society, 4 (1): 60-66.

Singh, B. P.; Koirala, I.; Jha, I. S. and Adhikari, D. (2014). The segregating nature of $\mathrm{Cd}-\mathrm{Pb}$ liquid binary alloys. Phys. Chem. Liq., 52 (4): 457-470.

Singh, R. N. and Sommer, F. (1992). Temperature dependence of thermodynamic functions of strongly interacting liquid alloys. J. Phys. Condens. Matter, 4: 5345.

Singh, R. N.; Mishra, I. K.; Singh, V. N. (1990). Local order in Cd-based liquid alloys. Phys. Condens. Matter, 2: 8457.

Warren, B. E. (1969). X-ray Diffraction. AddisonWesle, Reading MA. 227. 